Anne Greenough, Fabrice Decobert, David Field, Mikko Hallman, Helmut D. Hummler, Baldvin Jonsson, Manuel Sánchez Luna, Bart Van Overmeire, Virgilio P. Carnielli, Jim L. Potenziano and Jean-Christophe Mercier*

\title{
Inhaled nitric oxide (iNO) for preventing prematurity-related bronchopulmonary dysplasia (BPD): 7-year follow-up of the European Union Nitric Oxide (EUNO) trial
}

https://doi.org/10.1515/jpm-2020-0164

Received April 15, 2020; accepted August 8, 2020; published online September 7, 2020

\section{Abstract}

Objectives: Most studies of inhaled nitric oxide (iNO) for prevention of bronchopulmonary dysplasia (BPD) in premature infants have focused on short-term mortality and morbidity. Our aim was to determine the long-term effects of iNO.

Methods: A 7-year follow-up was undertaken of infants entered into a multicenter, double-blind, randomized, placebo-controlled trial of iNO for prevention of BPD in premature infants born between 24 and 28 weeks plus six days of gestation. At 7 years, survival and hospital admissions since the 2-year follow-up, home oxygen therapy in the past year, therapies used in the previous month and growth assessments were determined. Questionnaires were used to compare general health, well-being, and quality of life.

*Corresponding author: Jean-Christophe Mercier, MD, Professor Emeritus of Pediatrics, Université Paris Diderot, 47 Rue Copernic 75116, Paris, France, Phone: +33 6030180 80, E-mail: jeanchristophe.mercier@sfr.fr. https://orcid.org/0000-0001-7842-3378 Anne Greenough, King's College London, London, UK. https:// orcid.org/0000-0002-8672-5349

Fabrice Decobert, Centre Hospitalier Intercommunal de Créteil, Créteil, France

David Field, University of Leicester Centre for Medicine, Leicester, UK Mikko Hallman, University of Oulu and Oulu University Hospital, Oulu, Finland

Helmut D. Hummler, Sidra Medicine, Doha, Qatar; University of Ulm, Ulm, Germany

Baldvin Jonsson, Karolinska University Hospital and Institute, Stockholm, Sweden

Manuel Sánchez Luna, Hospital General Universitario "Gregorio Marañón," Madrid, Spain

Bart Van Overmeire, Université Libre de Bruxelles, Brussels, Belgium Virgilio P. Carnielli, Polytechnical University of Marche, Ancona, Italy Jim L. Potenziano, Mallinckrodt Pharmaceuticals, Bedminster, NJ, USA
Results: A total of 305 children were assessed. No deaths were reported. Rates of hospitalization for respiratory problems (6.6 vs. $10.5 \%$, iNO and placebo group, respectively) and use of respiratory medications (6.6 vs. 9.2\%) were similar. Two patients who received iNO and one who received placebo had received home oxygen therapy. There were no significant differences in any questionnairedocumented health outcomes.

Conclusions: iNO for prevention of BPD in very premature infants with respiratory distress did not result in long-term benefits or adverse long-term sequelae. In the light of current evidence, routine use of iNO cannot be recommended for prevention of BPD in preterm infants.

Keywords: bronchopulmonary dysplasia (BPD); inhaled nitric oxide; long-term outcomes.

\section{Introduction}

Bronchopulmonary dysplasia (BPD), which results in severe respiratory distress in premature infants, is associated with increased mortality, pulmonary hypertension, reduced lung function, increased airway obstruction, poor growth, and neurodevelopmental problems later in life [1-3]. Inhaled nitric oxide (iNO) is indicated to improve oxygenation and reduce the need for extracorporeal membrane oxygenation in term and near-term infants ( $>34$ weeks' gestation) with hypoxic respiratory failure associated with pulmonary hypertension [4]. While some prospective studies of iNO for prevention or treatment of BPD in preterm infants with severe respiratory failure have shown a benefit [5-7], most have not [8-14]. Most research regarding iNO for BPD prevention has focused on the short-term pathogenesis and prevention during the early neonatal period, rather than on long-term sequelae [1]. As with the original shortterm studies, longer-term studies of iNO for prevention of BPD-related outcomes in patients 1-5 years old have also 
yielded mixed results with regard to mortality, abnormal neurodevelopment, and medication use [15-21].

Primary results from the European Union Nitric Oxide (EUNO) study showed that iNO (INOmax®; Mallinckrodt Pharmaceuticals, Bedminster, NJ, USA) administered for prevention of BPD provided no improvement in survival without BPD at 36 weeks in preterm neonates born between 24 and 28 weeks plus 6 days gestational age with mild-tomoderate respiratory distress syndrome (RDS) compared with placebo ( 66 vs. $65 \%$, respectively, alive without BPD at 36 weeks' postmenstrual age) [12]. A follow-up study of the patients who had survived to 1 and 2 years of age showed no significant between-group difference in growth, neurological development or respiratory outcomes [20]. There have been no studies assessing outcomes of iNO usage after 5 years of age. Our aim was to assess the longterm effects of iNO usage at 7 years of age.

\section{Materials and methods}

\section{Study design and patients}

We assessed children who had been entered into the EUNO trial, which was a multicenter, double-blind, randomized, placebo-controlled study conducted in nine countries in the European Union (ClinicalTrials.gov Identifier: NCT00551642). The design has been described in detail previously [12] and is summarized here briefly. Infants born between 24 and 28 weeks plus 6 days of gestation, weighing $\geq 500 \mathrm{~g}$ and requiring surfactant within $24 \mathrm{~h}$ of birth (prophylactically or for signs of developing respiratory distress), or continuous positive airway pressure (CPAP) (fraction of inspired oxygen $\geq 0.3$ on mean airway pressure of $\geq 4 \mathrm{~cm}$ water) within $24 \mathrm{~h}$ to maintain an oxygen saturation of at least $85 \%$, were eligible for the study.

Patients were randomized one:one to iNO (5 ppm) or placebo (nitrogen gas) and stratified by study site and gestational age (2425 weeks plus 6 days and 26-28 weeks plus 6 days). Treatment was initiated within $2 \mathrm{~h}$ of eligibility and no later than $26 \mathrm{~h}$ of life and was continued for at least 7 days, up to a maximum of 21 days. Study gas was administered via an INOvent drug delivery system inserted into the patient's breathing circuit [12].

\section{Assessment and endpoints}

The 7-year follow-up was conducted by a member of the investigators' staff blinded to the group assignment. The outcomes were survival status and hospital admission since the 2-year followup, home oxygen therapy in the past year, therapies used in the month before the 7-year visit and vital signs, physical examination and growth assessment results. In addition, the Strengths and Difficulties Questionnaire (SDQ) and the Health Utilities Index (HUI) questionnaire were used to compare general health and well-being and quality of life between the iNO and placebo groups. The SDQ comprises 25 questions in five domains: emotional problems, conduct problems, hyperactivity, peer problems, and prosocial behavior, as well as a total difficulties scale [22]. Total scores on the subscales range from zero to 10 , with the total difficulties score ranging from zero to 40 (the prosocial domain is not incorporated into the total difficulties score) [22]. The HUI questionnaire contains 18 questions that were used to create the HUI2, which has six attributes, sensation, mobility, emotion, cognition, self-care and pain, and the HUI3, which has eight attributes, vision, hearing, speech, ambulation, dexterity, emotion, cognition, and pain [23]. Each attribute is scored on a four-, five-, or six-point scale, with higher scores indicating worse conditions. These scores were converted to single-attribute utility scores, with zero indicating most disabled and one indicating no disability. Based on the attribute levels of HUI2 and HUI3, two-level disability categories of none/mild and moderate/ severe were created. The HUI2 and HUI3 health status classification system and utility scoring functions were used to develop a HealthRelated Quality of Life (HRQOL) multi-attribute utility score, with values ranging from zero (dead) to one (healthy) [24].

\section{Data analysis}

The analysis population for the 7-year follow-up included all patients who received the study treatment (iNO or placebo) and had a completed 7-year case report form. No missing data imputation was performed. Comparisons between iNO and placebo were made using $t$ tests for continuous variables and Fisher exact test for categorical variables. All statistical tests were two-sided at a significance level of 0.05 .

Data were collected on a pre-designed case report form and entered into an Oracle Clinical database using a double-entry method and then converted to an internally validated SAS database for analysis. All analyses were conducted using SAS version 9.2 or higher.

Ethics

The study was approved by the appropriate regulatory authority in each country, and by the local Research Ethics Committee at each institution [12]. Informed consent for participation was obtained from parents.

\section{Results}

\section{Baseline characteristics}

Of the 702 patients who survived to 36 weeks gestational age across the 35 study sites participating in the primary study, 305 from 24 sites were assessed at the 7-year follow-up (iNO, $n=152 / 305$ [49.8\%]; placebo, $n=153 / 305$ [50.2\%]) (Figure 1). A total of $397 / 702$ (56.6\%) original survivors were lost to 7-year follow-up; 209/702 (29.8\%) because their study sites $(\mathrm{n}=11)$ discontinued study participation prior to the 7-year assessments and 188/702 (26.8\%) across the 24 study sites that continued participation in the study through the 7-year follow-up. Baseline characteristics and major morbidities 
during the first hospitalization of patients in the 7-year follow-up cohorts are shown in Table 1. Characteristics of the cohort included in the current analysis were similar to those of patients in the original EUNO study [12].

\section{Survival and other outcomes}

There were no deaths reported from the end of the 2-year follow-up to the 7-year follow-up. Overall, rates of hospitalizations during this period were $28.9 \%$ and $34.6 \%$ in the iNO and placebo groups, respectively ( $\mathrm{p}=0.29)$, with $6.6 \%$ of patients hospitalized for respiratory/breathing difficulties in the iNO group compared to $10.5 \%$ in the placebo group $(\mathrm{p}=0.23$; Table 2). Growth assessment results were comparable in the study groups. The mean (standard deviation [SD]) weight was 23.0 (6.78) $\mathrm{kg}$ and $22.6(4.63) \mathrm{kg}$ in the iNO and placebo groups $(\mathrm{p}=0.58)$, respectively; mean (SD) length was $121.3(6.15) \mathrm{cm}$ and $120.6(6.40) \mathrm{cm}(\mathrm{p}=0.35)$, respectively. There were no significant differences in physical examination results (Supplementary Table 1).

\section{Therapies and medications}

Two (1.3\%) patients in the iNO group and one (0.7\%) in the placebo group received home oxygen therapy during the year prior to the 7 -year follow-up ( $\mathrm{p}=0.56)$. Overall, $20 \%$ of patients were receiving supportive therapy, with no difference between the study groups $(\mathrm{p}=0.86)$. Twelve $(7.9 \%)$ patients in the iNO group and nine (5.9\%) in the placebo group were receiving speech therapy ( $\mathrm{p}=0.49)$, and $15(9.9 \%)$ and nine $(5.9 \%)$, respectively, were receiving physical therapy
Table 1: Baseline characteristics during the first hospitalization.

\begin{tabular}{|c|c|c|}
\hline Variable & $\begin{array}{l}\text { Inhaled nitric oxide } \\
(\mathrm{n}=152)\end{array}$ & $\begin{array}{l}\text { Placebo } \\
(n=153)\end{array}$ \\
\hline $\begin{array}{l}\text { Gestational age at birth, mean } \\
\text { (SD), weeks }\end{array}$ & $26.6(1.16)$ & $26.5(1.35)$ \\
\hline$<26$ weeks, n (\%) & $39(25.7)$ & $54(35.3)$ \\
\hline$\geq 26$ weeks, n (\%) & $113(74.3)$ & $99(64.7)$ \\
\hline Birth weight, mean (SD), g & $870.2(197.34)$ & $\begin{array}{r}885.3 \\
(188.24)\end{array}$ \\
\hline Birth length, mean (SD), $\mathrm{cm}$ & $34.1(2.82)^{a}$ & $33.9(3.07)^{b}$ \\
\hline Male sex, n (\%) & $75(49.3)$ & $83(54.2)$ \\
\hline \multicolumn{3}{|l|}{ Mother's race ${ }^{c}, \mathrm{n}(\%)$} \\
\hline White & $125(82.2)$ & $137(89.5)$ \\
\hline Black & $14(9.2)$ & $10(6.5)$ \\
\hline Other & $13(8.6)$ & $6(3.9)$ \\
\hline $\begin{array}{l}\text { 5-min Apgar score, median } \\
\quad \text { (range) }\end{array}$ & $8.0(2.0,10.0)^{d}$ & $8.0(0,10)^{\mathrm{e}}$ \\
\hline $\begin{array}{l}\text { Exposure to study drug, mean } \\
\text { (SD), days }\end{array}$ & $17.6(5.49)$ & $17.9(5.47)$ \\
\hline
\end{tabular}

${ }^{a} n=125 .{ }^{b} n=127 .{ }^{c}$ Self-reported by the parents of the patient. ${ }^{d} n=147$. $e_{n=150}$.

$(\mathrm{p}=0.20)$. Seven $(4.6 \%)$ patients in the iNO group and 15 $(9.8 \%)$ in the placebo group were receiving some other therapy (i.e., not speech or physical therapy) $(\mathrm{p}=0.08)$.

Proportions of patients taking respiratory medications were similar in both study groups. Ten patients (6.6\%) randomized to iNO and $14(9.2 \%)$ randomized to placebo were currently taking respiratory medications at the 7 -year followup $(\mathrm{p}=0.40)$. The most commonly used respiratory medications were inhaled corticosteroids (six iNO patients [3.9\%] and 11 placebo patients [7.2\%]; $p=0.22$ ), and $\beta 2$-adrenergic receptor agonists (five iNO patients [3.3\%] and eight [5.2\%] placebo patients, respectively; $\mathrm{p}=0.40)$. Seventeen patients $(11.2 \%)$

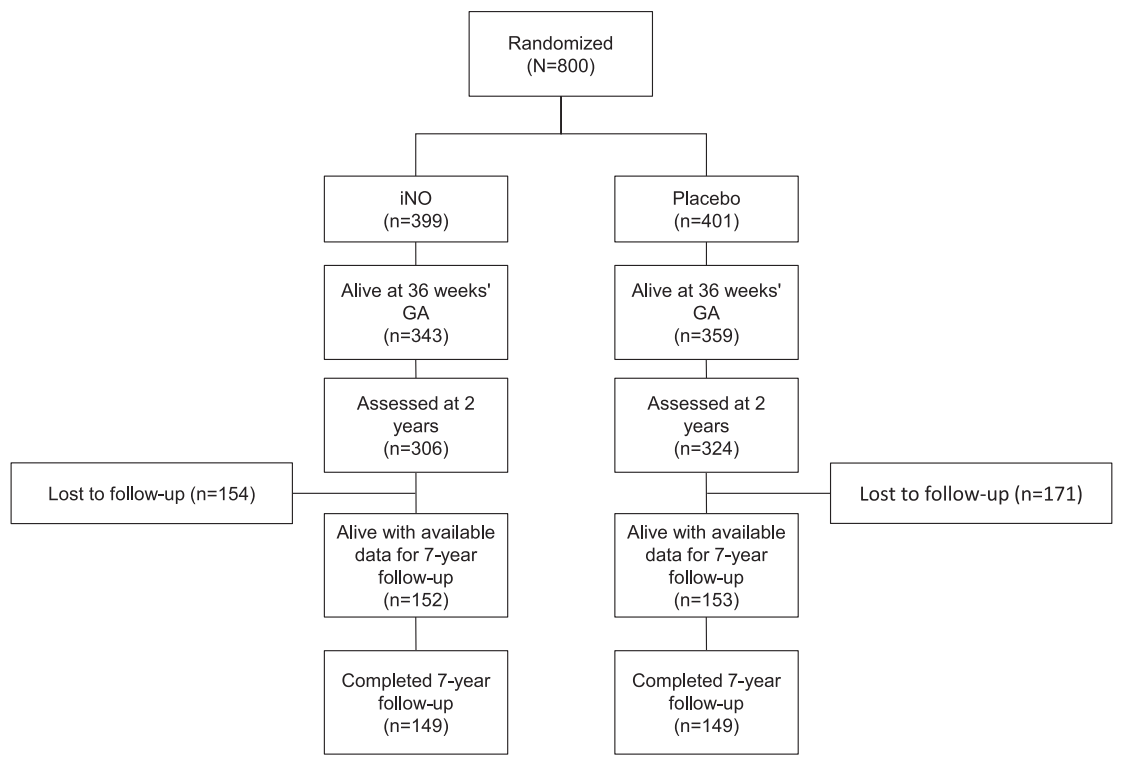

Figure 1: Patient disposition. $\mathrm{GA}$, gestational age; iNO, inhaled nitric oxide. 
Table 2: In-hospital admissions between 2-and 7-year follow-up.

\begin{tabular}{lccr}
\hline Category & $\begin{array}{c}\text { Inhaled nitric } \\
\text { oxide }(\mathbf{n = 1 5 2 )})\end{array}$ & $\begin{array}{c}\text { Placebo } \\
(\mathbf{n = 1 5 3 )}\end{array}$ & $\begin{array}{r}\text { p- } \\
\text { Value }\end{array}$ \\
\hline $\begin{array}{l}\text { Admitted to hospital since } \\
\text { the 2-year visit }\end{array}$ & $44(28.9)$ & $53(34.6)$ & 0.29 \\
$\begin{array}{l}\text { Hospitalized for respiratory/ } \\
\text { breathing difficulties }\end{array}$ & $10(6.6)$ & $16(10.5)$ & 0.22 \\
$\begin{array}{l}\text { Hospitalized for surgery } \\
\text { Hospitalized for other }\end{array}$ & $33(21.7)$ & $32(20.9)$ & 0.87 \\
$\quad \begin{array}{l}\text { reason } \\
\quad \begin{array}{l}\text { Admitted to ICU } \\
\text { Required mechanical }\end{array}\end{array}$ & $14(9.2)$ & $16(10.5)$ & 0.72 \\
$\quad$ ventilation & $6(3.9)$ & $3(2.0)$ & 0.31 \\
\hline
\end{tabular}

Data are shown as $\mathrm{n}(\%)$; ICU, intensive care unit.

and $15(9.8 \%)$ in the iNO and placebo groups, respectively, were receiving non-respiratory medications $(\mathrm{p}=0.69)$.

\section{Health outcomes questionnaires}

Results of the SDQ were generally similar in the placebo and iNO groups overall and with regard to conduct problems, hyperactivity and prosocial scales (Table 3 ). There were no significant differences in the emotional problems category (125/147 [85.0\%] vs. 113/147 [76.9\%]; $p=0.10)$. HUI2 and HUI3 results were similar in both groups for all attributes (Table 4).

\section{Discussion}

This study demonstrated that iNO had no significant effect on mortality, growth, hospitalization, outpatient therapy, medication use, HRQOL and overall health outcomes at 7 years of follow-up in premature infants. The current data set represents the longest duration of neurodevelopmental follow-up to date in patients treated with iNO for prevention of BPD and its consequences.

There have been a number of studies assessing longterm outcomes from randomized controlled studies of iNO, but they have usually been when the participants have been at one to two years of corrected age. Several studies have shown that neurodevelopmental outcome is not adversely affected by iNO $[15,18]$ but only one showed that it has been improved at approximately two years of age [19]. In this one, a single-center trial, adverse neurodevelopmental outcomes were lower in the iNO-treated group vs. placebo (24 vs. 46\%) [19]. All of those studies used a higher dose of iNO than in the trial for which we report the 7-year follow-up. A Cochrane review published in 2017 demonstrated no significant impact of iNO on neurodevelopment impairment [25].
Table 3: Strengths and Difficulties Questionnaire (SDQ) results for patients with 7 year follow-up data.

\begin{tabular}{|c|c|c|c|}
\hline Category & $\begin{array}{l}\text { Inhaled nitric oxide } \\
(\mathrm{n}=147)\end{array}$ & $\begin{array}{l}\text { Placebo } \\
(n=147)\end{array}$ & $\begin{array}{l}\text { p- } \\
\text { Value }\end{array}$ \\
\hline $\begin{array}{l}\text { Emotional problems } \\
\text { scale }^{\mathrm{a}}\end{array}$ & 1.9 (1.79) & $2.1(1.96)$ & 0.24 \\
\hline $\begin{array}{l}\text { Conduct problems } \\
\text { scale }^{\text {b }}\end{array}$ & $1.4(1.55)$ & $1.4(1.58)$ & 1.00 \\
\hline Hyperactivity scale ${ }^{c}$ & $3.8(2.64)$ & $3.4(2.66)$ & 0.30 \\
\hline Peer problems scale ${ }^{b}$ & $1.2(1.41)$ & $1.5(1.74)$ & 0.13 \\
\hline Prosocial scale $^{d}$ & $8.6(1.73)$ & $8.4(1.81)$ & 0.25 \\
\hline $\begin{array}{l}\text { Total difficulties } \\
\text { scale }^{\mathrm{e}}\end{array}$ & $8.3(5.04)$ & $8.5(5.76)$ & 0.72 \\
\hline
\end{tabular}

Data are shown as mean (SD). ${ }^{\mathrm{a}} 0-3$ is normal; 4 is borderline; $5-10$ is abnormal. ${ }^{b} 0-2$ is normal; 3 is borderline; $4-10$ is abnormal. ${ }^{c} 0-5$ is normal; 6 is borderline; $7-10$ is abnormal. ${ }^{\mathrm{d}} 6-10$ is normal; 5 is borderline; $0-4$ is abnormal. ${ }^{e} 0-13$ is normal; $14-16$ is borderline; $17-40$ is abnormal.

Table 4: Summary of Health Utility Index Mark 2 (HUI2) and Mark 3 (HUI3) single-attribute scores.

\begin{tabular}{lcll}
\hline Attribute & $\begin{array}{l}\text { Inhaled nitric oxide } \\
(\mathbf{n = 1 5 2 )}\end{array}$ & $\begin{array}{l}\text { Placebo } \\
(\mathbf{n = 1 5 3 )}\end{array}$ & p-Value \\
\hline HUI2 & $0.9(0.17)^{\mathrm{a}}$ & $0.9(0.16)^{\mathrm{b}}$ & 0.97 \\
Sensation & $1.0(0.14)^{\mathrm{c}}$ & $1.0(0.08)^{\mathrm{d}}$ & 0.39 \\
Mobility & $1.0(0.08)^{\mathrm{b}}$ & $1.0(0.09)^{\mathrm{e}}$ & 0.84 \\
Emotion & $1.0(0.13)^{\mathrm{e}}$ & $1.0(0.13)^{\mathrm{d}}$ & 0.87 \\
Cognition & $1.0(0.20)^{\mathrm{b}}$ & $1.0(0.12)^{\mathrm{d}}$ & 0.18 \\
Self-care & $1.0(0.05)^{\mathrm{b}}$ & $1.0(0.03)^{\mathrm{b}}$ & 0.07 \\
Pain & & & \\
HUl3 & & & \\
Vision & $1.0(0.14)^{\mathrm{c}}$ & $1.0(0.06)^{\mathrm{d}}$ & 0.22 \\
Hearing & $1.0(0.07)^{\mathrm{e}}$ & $1.0(0.03)^{\mathrm{d}}$ & 0.17 \\
Speech & $1.0(0.14)^{\mathrm{c}}$ & $1.0(0.14)^{\mathrm{b}}$ & 0.90 \\
Ambulation & $1.0(0.15)^{\mathrm{c}}$ & $1.0(0.11)^{\mathrm{d}}$ & 0.55 \\
Dexterity & $1.0(0.13)^{\mathrm{b}}$ & $1.0(0.07)^{\mathrm{d}}$ & 0.22 \\
Emotion & $1.0(0.02)^{\mathrm{b}}$ & $1.0(0.02)^{\mathrm{b}}$ & 0.83 \\
Cognition & $0.9(0.15)^{\mathrm{e}}$ & $0.9(0.17)^{\mathrm{d}}$ & 0.96 \\
Pain & $1.0(0.07)^{\mathrm{b}}$ & $1.0(0.07)^{\mathrm{d}}$ & 0.44 \\
\hline
\end{tabular}

Data are shown as mean (SD); higher attribute scores indicate worse conditions. ${ }^{a} n=144 .{ }^{b} n=147 .{ }^{c} n=146 .{ }^{d} n=148 .{ }^{e} n=145$.

Longer follow-up studies have been carried out. For example, following the INNOVO trial, at 4-5 years of age there was no significant difference in the results of cognitive and behavioral assessments with iNO vs. controls [21]. Two studies have looked at school-aged children. One assessing children at a mean age of 5.7 years from a single-center randomized controlled trial demonstrated no significant differences in school readiness, growth parameters or need for subsequent hospitalization, but a $(\mathrm{p}=0.05)$ reduction in technology dependence and functional disability [26]. In a single-center follow-up study of children at 7-9 years of age 
from the multicenter randomized controlled NO CLD study, no significant differences were found in pulmonary function or exercise capacity, with $63 \%$ of survivors followed up [27].

The current study population was $86 \%$ Caucasian and only $8 \%$ black. It has been suggested that white patients may be less likely to benefit from iNO treatment than black patients $[5,8]$. A recent meta-analysis of trials that provided data according to race, reported by Askie and colleagues [28], found that African American infants had a statistically significant reduction in risk of BPD or death at 36 weeks following iNO treatment ( $p=0.003)$, but that white and Hispanic infants did not. It should, however, be noted that the meta-analysis assumed that black infants were African American and did not provide information on whether or how race was determined beyond maternal selfreport, nor did it assess long-term outcomes. A recent retrospective study [29] of iNO in a large cohort of premature African American $(n=356)$, white $(n=502)$, and Hispanic $(n=258)$ neonates did not corroborate the results reported by Askie and colleagues [28]. The complexity of the association between race/ethnicity and BPD risk is highlighted by the results of a genome-wide association study of iNO in 387 high-risk preterm infants [30]. In that study, improved survival without BPD in iNO-treated infants was seen in selfreported Hispanic white mothers, but not self-reported black/African American mothers.

The iNO trials conducted to date in preterm infants have included a range of patient populations (gestational ages ranging from 24-28 weeks to $<34$ weeks) and different strategies (initiation of iNO at different times after birth and duration of iNO administration), making it difficult to interpret overall study results [5-14]. Small for gestational age infants are at high risk of adverse outcomes including severe BPD [31], increased rehospitalization, and need for chest medications at follow-up [32]. There is no evidence, however, from randomized controlled trials that iNO will particularly benefit this group. Retrospective evidence suggests that prematurely born infants with premature and prolonged rupture of the membranes with severe hypoxemic respiratory failure may be a targeted group for iNO therapy [33]. Aside from race, as mentioned above, it is unclear whether a particular patient population or specific iNO dosing or other treatment strategy may predict a better response to iNO in the short term, and if any of these factors would impact the long-term benefit.

This study has strengths and some limitations. This is the first study to assess the outcomes of very prematurely born infants at 7 years of age who had been entered into a neonatal randomized trial of iNO. We were able to assess 305 children and thus another strength of our study was that we report the 7-year outcomes of a large number of children who were all born before 29 weeks of gestation. Unfortunately, 11 of the original 35 study centers did not participate in the 7-year follow-up. Nevertheless, the iNO and placebo groups were well balanced, with characteristics similar to those of the original randomized population [12]. This suggests that the results of our study reflect the overall population. Furthermore, there was not an unbalanced bias in the 2-year follow-up between the two groups iNO vs. placebo [20]. In addition, in the current 7-year follow-up study that was still blinded, the significant loss to follow-up came from the decision of 11 centers not to pursue the long-term follow-up, because of both lack of interest and funding. Therefore, although we cannot prove it, it is very unlikely there would be an unbalanced introduced factor between the two groups.

A criticism of our trial is that a proportion of the population was not intubated, and hence they may not have received sufficient iNO. In a randomized prospective, double-blind, crossover trial of administering iNO to preterm infants on CPAP for RDS, a significant improvement in oxygenation was seen suggesting that iNO can be delivered effectively non-invasively [34].

In conclusion, there were no meaningful betweengroup differences observed for any assessments conducted during the 7-year follow-up period. iNO for prevention of BPD in infants with respiratory distress born at 24-28 weeks and 6 days gestational age was then not associated with improved long-term outcomes or adverse effects. In the light of current evidence, routine use of iNO cannot be recommended for prevention of BPD in preterm infants.

Acknowledgments: We would like to thank Mrs. Deirdre Gibbons for her kind help in secretarial assistance. The publication of this article was funded by the Qatar National Library.

Research funding: This study was sponsored by Mallinckrodt Pharmaceuticals. Medical writing and editorial support was provided by Michael D. Morren, RPh, MBA, of Peloton Advantage, Dana Torchia, MBA, LLC, an OPEN Health company, sponsored by Mallinckrodt Pharmaceuticals.

Author contributions: VPC conceptualized and designed the study, served as study investigator, and enrolled patients; FD served as study investigator, enrolled patients, and collected data; DF served as principal investigator and study investigator, enrolled patients, and collected, analyzed, and interpreted data; AG served as study investigator; $\mathrm{MH}$ served as study investigator, enrolled patients, and collected, analyzed, and interpreted data; HDH conceptualized and designed the study, served as principal investigator and study investigator, enrolled patients, and collected, analyzed, and interpreted data; BJ served as principal investigator and study investigator, enrolled patients, and analyzed and interpreted 
data; JCM conceptualized and designed the study and served as principal investigator; JLP collected, analyzed, and interpreted data; and MSL conceptualized and designed the study, enrolled patients, and served as study investigator. All authors have accepted responsibility for the entire content of this manuscript and approved its submission.

Competing interests: AG has held grants from and has received honoraria for giving lectures and advising, various manufacturers (Abbott Laboratories, MedImmune) and ventilator manufacturers (SLE). She is currently receiving a nonconditional educational grant from SLE. JLP is an employee of Mallinckrodt Pharmaceuticals and may hold stock or stock options in that company. The other authors have no conflicts of interest relevant to this article to disclose. Clinical trial registration number and registry name: ClinicalTrials.gov Identifier: NCT00551642. Safety and efficacy study of nitric oxide for inhalation on chronic lung disease in premature babies.

Data sharing statement: The datasets generated and analyzed for this manuscript are not publicly available. Primary data for this study can be found at https://clinicaltrials.gov (ClinicalTrials.gov Identifier: NCT00551642). Requests for additional information should be made to the corresponding author.

\section{References}

1. Abman SH, Collaco JM, Shepherd EG, Keszler M, Cuevas-Guaman $M$, Welty SE, et al. Interdisciplinary care of children with severe bronchopulmonary dysplasia. J Pediatr 2017;181:12-28.e1.

2. Mandell EW, Abman SH. Fetal vascular origins of bronchopulmonary dysplasia. J Pediatr 2017;185:7-10.e1.

3. Bui CB, Pang MA, Sehgal A, Theda C, Lao JC, Berger PJ, et al. Pulmonary hypertension associated with bronchopulmonary dysplasia in preterm infants. J Reprod Immunol 2017;124:21-9.

4. INOmax [package insert]. Bedminster, NJ: INO Therapeutics, 2019.

5. Ballard RA, Truog WE, Cnaan A, Martin RJ, Ballard PL, Merrill JD, et al. Inhaled nitric oxide in preterm infants undergoing mechanical ventilation: the NO CLD study group. N Engl J Med 2006;355:343-53.

6. Dani C, Bertini G, Pezzati M, Filippi L, Cecchi A, Rubaltelli FF. Inhaled nitric oxide in very preterm infants with severe respiratory distress syndrome. Acta Paediatr 2006;95:1116-23.

7. Schreiber MD, Gin-Mestan K, Marks JD, Huo D, Lee G, Srisuparp P. Inhaled nitric oxide in premature infants with the respiratory distress syndrome. N Engl J Med 2003;349:2099-107.

8. Hasan SU, Potenziano J, Konduri GG, Perez JA, Van Meurs KP, Walker MW, et al. Effect of inhaled nitric oxide on survival without bronchopulmonary dysplasia in preterm infants: a randomized clinical trial. JAMA Pediatr 2017;171:1081-9.

9. Field D, Elbourne D, Truesdale A, Grieve R, Hardy P, Fenton AC, et al. Neonatal ventilation with inhaled nitric oxide versus ventilatory support without inhaled nitric oxide for preterm infants with severe respiratory failure: the INNOVO multicentre randomised controlled trial (ISRCTN 17821339). Pediatrics 2005;115:926-36.
10. Jiang Q, Gao X, Liu C, Chen D, Lin X, Xia S, et al. Early inhaled nitric oxide in preterm infants $<34$ weeks with evolving bronchopulmonary dysplasia. J Perinatol 2016;36:883-9.

11. Kinsella JP, Cutter GR, Walsh WF, Gerstmann DR, Bose CL, Hart C, et al. Early inhaled nitric oxide therapy in premature newborns with respiratory failure. N Engl J Med 2006;355:354-64.

12. Mercier JC, Hummler H, Durrmeyer X, Sanchez-Luna M, Carnielli V, Field $D$, et al. Inhaled nitric oxide for prevention of bronchopulmonary dysplasia in premature babies (EUNO): a randomised controlled trial. Lancet 2010;376:346-54.

13. Subhedar NV, Ryan SW, Shaw NJ. Open randomised controlled trial of inhaled nitric oxide and early dexamethasone in high risk preterm infants. Arch Dis Child Fetal Neonatal Ed 1997;77:F185-90.

14. Van Meurs KP, Wright LL, Ehrenkranz RA, Lemons JA, Ball MB, Poole WK, et al. Inhaled nitric oxide for premature infants with severe respiratory failure. N Engl J Med 2005;353:13-22.

15. Walsh MC, Hibbs AM, Martin CR, Cnaan A, Keller RL, Vittinghoff E, et al. Two-year neurodevelopmental outcomes of ventilated preterm infants treated with inhaled nitric oxide. J Pediatr 2010; 156:556-61.

16. Bennett AJ, Shaw NJ, Gregg JE, Subhedar NV. Neurodevelopmental outcome in high-risk preterm infants treated with inhaled nitric oxide. Acta Paediatr 2001;90:573-6.

17. Hibbs AM, Walsh MC, Martin RJ, Truog WE, Lorch SA, Alessandrini $E$, et al. One-year respiratory outcomes of preterm infants enrolled in the nitric oxide (to prevent) chronic lung disease trial. J Pediatr 2008;153:525-9.

18. Hintz SR, Van Meurs KP, Perritt R, Poole WK, Das A, Stevenson DK, et al. Neurodevelopmental outcomes of premature infants with severe respiratory failure enrolled in a randomized controlled trial of inhaled nitric oxide. J Pediatr 2007;151:16-22.

19. Mestan KK, Marks JD, Hecox K, Huo D, Schreiber MD. Neurodevelopmental outcomes of premature infants treated with inhaled nitric oxide. N Engl J Med 2005;353:23-32.

20. Durrmeyer X, Hummler H, Sanchez-Luna M, Carnielli VP, Field D, Greenough A, et al. Two-year outcomes of a randomized controlled trial of inhaled nitric oxide in premature infants. Pediatrics 2013;132:e695-703.

21. Huddy CL, Bennett CC, Hardy P, Field D, Elbourne D, Grieve R, et al. The INNOVO multicentre randomised controlled trial: neonatal ventilation with inhaled nitric oxide versus ventilatory support without nitric oxide for severe respiratory failure in preterm infants: follow up at $4-5$ years. Arch Dis Child Fetal Neonatal Ed 2008;93:F430-F5.

22. Goodman R. The strengths and difficulties questionnaire: a research note. J Child Psychol Psychiatry 1997;38:581-6.

23. Feeny D, Furlong W, Boyle M, Torrance GW. Multi-attribute health status classification systems. Health Utilities Index. Pharmacoeconomics 1995;7:490-502.

24. Furlong WJ, Feeny DH, Torrance GW. Health utilities index procedures manual for self-administered questionnaires. Dundas, ON, Canada: Health Utilities Inc.; 2002.

25. Barrington KJ, Finer N, Pennaforte T. Inhaled nitric oxide for respiratory failure in preterm infants. Cochrane Database Syst Rev 2017;1:Cd000509.

26. Patrianakos-Hoobler Al, Marks JD, Msall ME, Huo D, Schreiber MD. Safety and efficacy of inhaled nitric oxide treatment for premature infants with respiratory distress syndrome: follow-up evaluation at early school age. Acta Paediatr 2011;100: 524-8. 
27. Kilbride H, Escobar H, Holmes A, Teson K, Truog W. Childhood pulmonary function, exercise capacity, and exhaled nitric oxide levels: outcomes following neonatal treatment with inhaled nitric oxide to prevent bronchopulmonary dysplasia. Am J Perinatol 2019;36:360-5.

28. Askie LM, Davies LC, Schreiber MD, Hibbs AM, Ballard PL, Ballard RA. Race effects of inhaled nitric oxide in preterm infants: an individual participant data meta-analysis. J Pediatr 2018;193:34-9.e2.

29. Collura CA, Mara KC, Weaver AL, Clark RH, Carey WA. Outcomes of early inhaled nitric oxide use in premature African American neonates. J Perinatol 2018;38:1657-65.

30. Torgerson DG, Ballard PL, Keller RL, Oh SS, Huntsman S, Hu D, et al. Ancestry and genetic associations with bronchopulmonary dysplasia in preterm infants. Am J Physiol Lung Cell Mol Physiol 2018;315:L858-169.

31. Charles E, Hunt KA, Harris C, Hickey A, Greenough A. Small for gestational age and extremely low birth weight infant outcomes. J Perinat Med 2019;47:247-51.
32. Peacock JL, Lo JW, D'Costa W, Calvert S, Marlow N, Greenough A. Respiratory morbidity at follow-up of small-for-gestationalage infants born very prematurely. Pediatr Res 2013;73:45763.

33. Chandrasekharan P, Kozielski R, Kumar VH, Rawat M, Manja V, Ma C, et al. Early use of inhaled nitric oxide in preterm infants: is there a rationale for selective approach? Am J Perinatol 2017; $34: 428-40$.

34. Lindwall R, Blennow M, Svensson M, Jonsson B, BerggrenBostrom $E$, Flanby $M$, et al. A pilot study of inhaled nitric oxide in preterm infants treated with nasal continuous positive airway pressure for respiratory distress syndrome. Intensive Care Med 2005;31:959-64.

Supplementary Material: The online version of this article offers supplementary material (https://doi.org/10.1515/.jpm-2020-0164). 